\title{
AC 2008-1066: A STUDY IN ENGINEERING AND MILITARY ETHICS
}

\section{Gayle Davis, United States Military Academy}

Gayle E. Davis is an Instructor in the Environmental Engineering Program at the United States Military Academy and an officer in the United States Army. Her teaching interests include introductory level environmental engineering as well as hazardous and solid waste.

Michael Butkus, United States Military Academy 


\section{A Study in Engineering and Military Ethics}

\section{Introduction}

Human nature and social awareness can often cause individuals to act or make decisions that are not considered moral or proper by the majority. Merriam-Webster defines ethics as a set of moral principles or a system of moral values. ${ }^{1}$ Most occupations that require the trust of the general public are held to high ethical standards. These professions include law, medical, engineering, and military, all of which have adopted systems that guide subscribed individuals through moral decision making processes. Most learned professions that uphold such standards prescribe a system of non-mandatory codes of conduct. ${ }^{2}$ Perhaps the most recognized professional code of ethics was reported by the National Society of Professional Engineers, which defines fundamental canons and includes explicit guidance on professional conduct.

Because ethical behavior is essential to the profession of engineering, ABET Inc., has addressed this topic in Criterion 3, outcome (f): graduates will have an understanding of professional and ethical responsibility. The environmental engineering program criteria (ABET

Criterion 9) also requires an understanding of professional practice issues. ${ }^{3}$ There are numerous examples in the literature on how professional practice issues might be included in engineering curricula, but limited data on methods for assessment.

The United States Military Academy (USMA) Environmental Engineering Program has a robust military ethical education and training program that spans the entire four year West Point experience. It is thought that the moral character development programs at USMA strongly support the professional practice requirements of EC2000. ${ }^{3}$ The USMA environmental engineering program has been assessing attainment of ethics and other professional practice requirements since ca. 1999. Because all graduates of the USMA environmental engineering program (unless granted a waiver by the program director) are required to take the Fundamentals of Engineering Exam (FEE), it has been used as a metric for this purpose since FEE subject data has been available. Longitudinal data on ethics questions, from the FEE, is presented in Figure 1. The USMA Environmental Engineering cadets have been tracking with the national average (for environmental engineers) on ethics since 2002. 


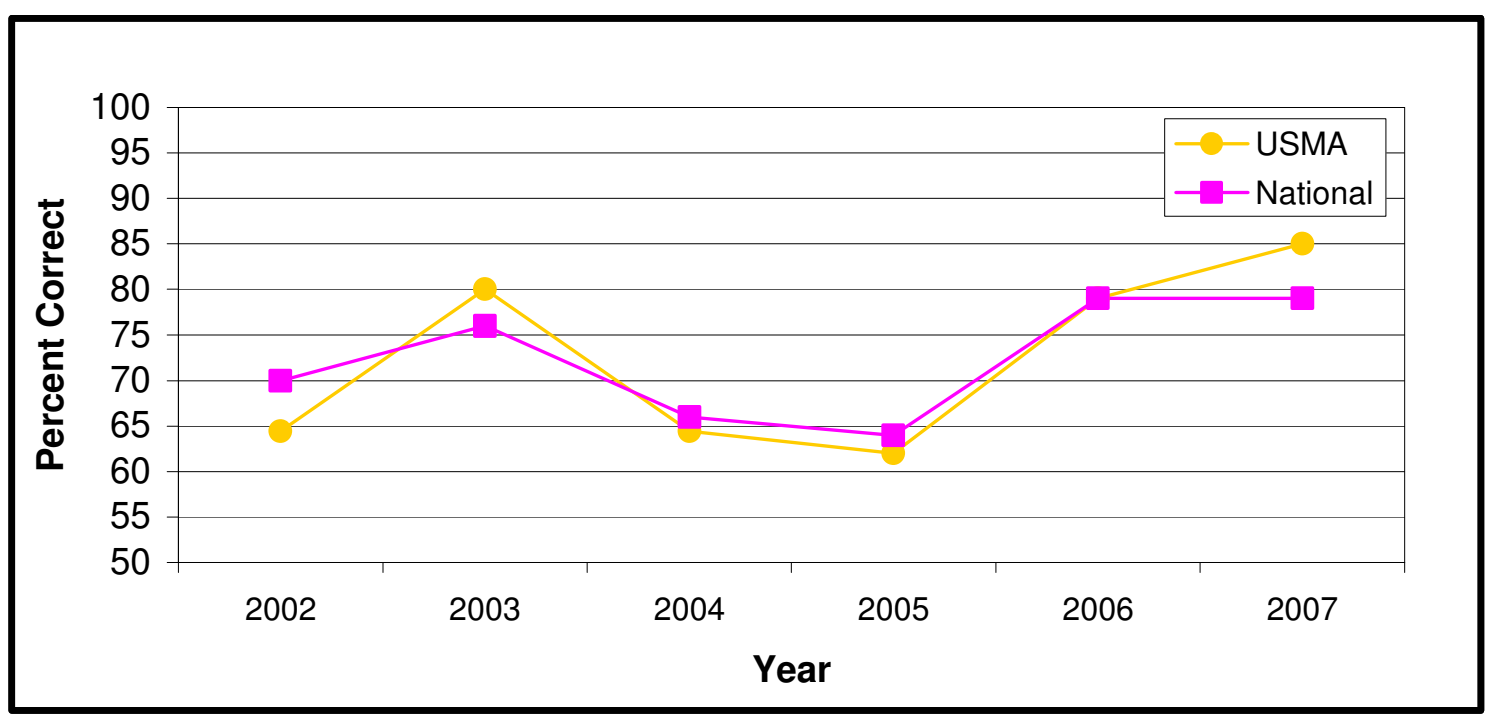

Figure 1. Longitudinal data for the USMA Environmental Engineering Program's Performance on Ethics on the Fundamentals of Engineering Exam (Spring).

Cadet performance on FEE ethics questions for all USMA Engineering Programs in spring 2007 is presented in Figure 2. The USMA weighted average was $80 \%$, which is comparable to the national average (for environmental engineers) of 79\%. Although some programs performed slightly better than others, the 2007 data suggest that USMA engineering cadets perform on par with engineering graduates at the national level.

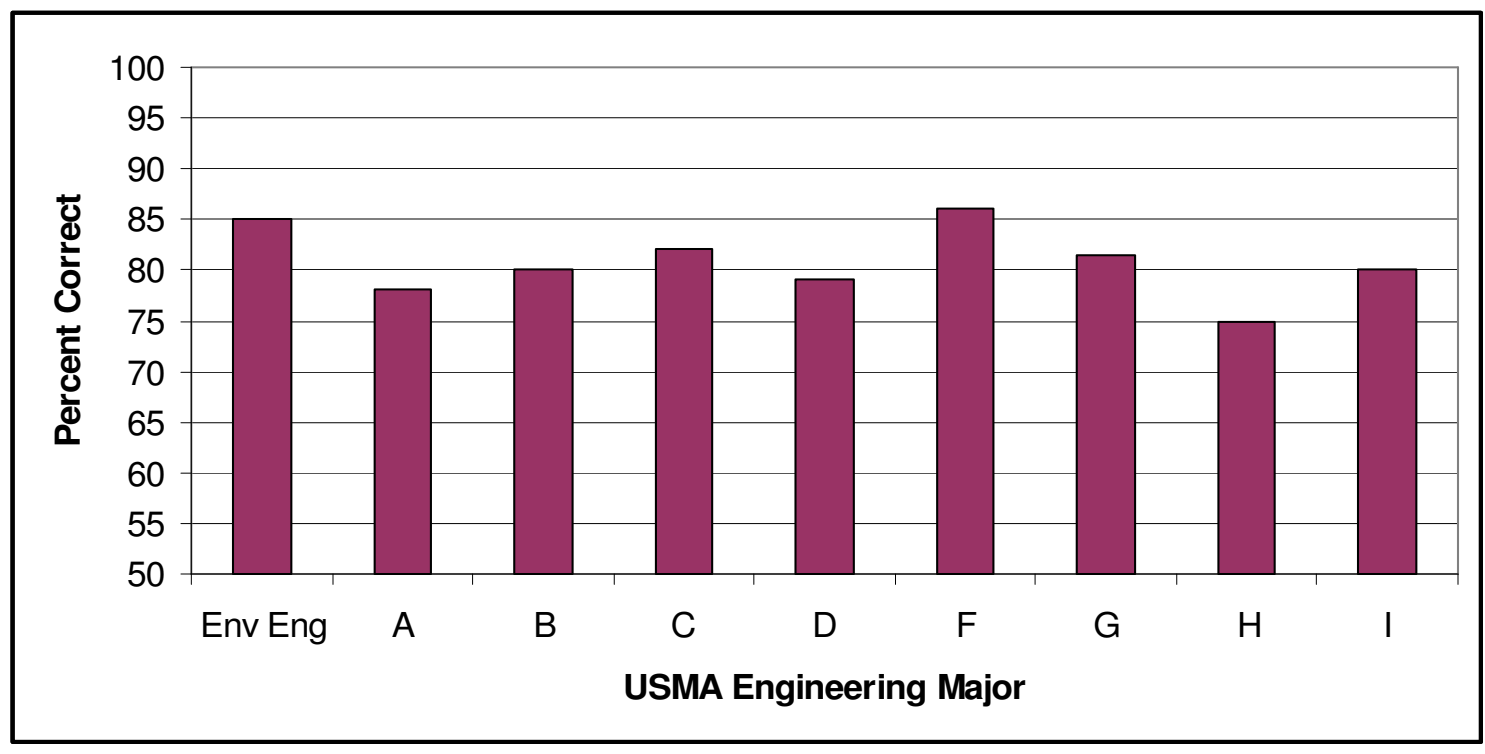

Figure 2. Cadet performance on FEE ethics questions (8 total) for all USMA Engineering Programs in spring 2007. Letters on the abscissa represent one of the other nine engineering programs at USMA. The overall USMA weighted average was $80 \%$ and the environmental engineering national average was $79 \%$. 
Given the substantial amount of education and training on ethics at USMA (vida infra) it was expected that longitudinal data for environmental engineering program graduates would be above the national average on the ethics section of the FEE. Consequently, a study was conducted to assess development of professional practice issues in the USMA Environmental Engineering Program. The purpose of this work were to (a) compare and contrast military ethics and engineering ethics; (b) determine if cadet performance on engineering ethics questions on the FEE improves as a result of the education and training at USMA; and, (c) present a suitable strategy for assessing and evaluating engineering ethics in undergraduate programs. The findings presented herein are extensible to all engineering programs (military schools, ROTC programs, etc) that are considering the use of military doctrine to help provide students with the competence to resolve problems with engineering ethics post graduation.

\section{Background}

Because much of the cadets' exposure to professional practice issues is based on military doctrine, the military ethic is compared with engineering ethics as a starting point. First, it is acknowledged that both engineers and military officers are considered to be part of a profession rather than an occupation. Both have a base set of skills and knowledge that requires in depth training, whether technical engineering skills or tactical military skills, which is particularly important to public safety and public well being. In addition, both professions uphold themselves to be self-regulating, meaning that the profession itself takes great pride in ensuring that other members of the profession are held to the high moral standards that guide the ethical conduct of each. ${ }^{4}$

The USMA Cadet Leader Development Systems, built upon a historical curriculum, is the foundation needed to develop the cadet's individual character such that the actions of graduates are made on sound moral principles. There is no single document that delineates the overall USMA ethics training and education programs. The major documents that shape the curriculum on military ethics are presented in Figure 3. The USMA 47 month experience exposes all cadets to numerous ethical education and training events (Figure 4, "Academy Curriculum"). 


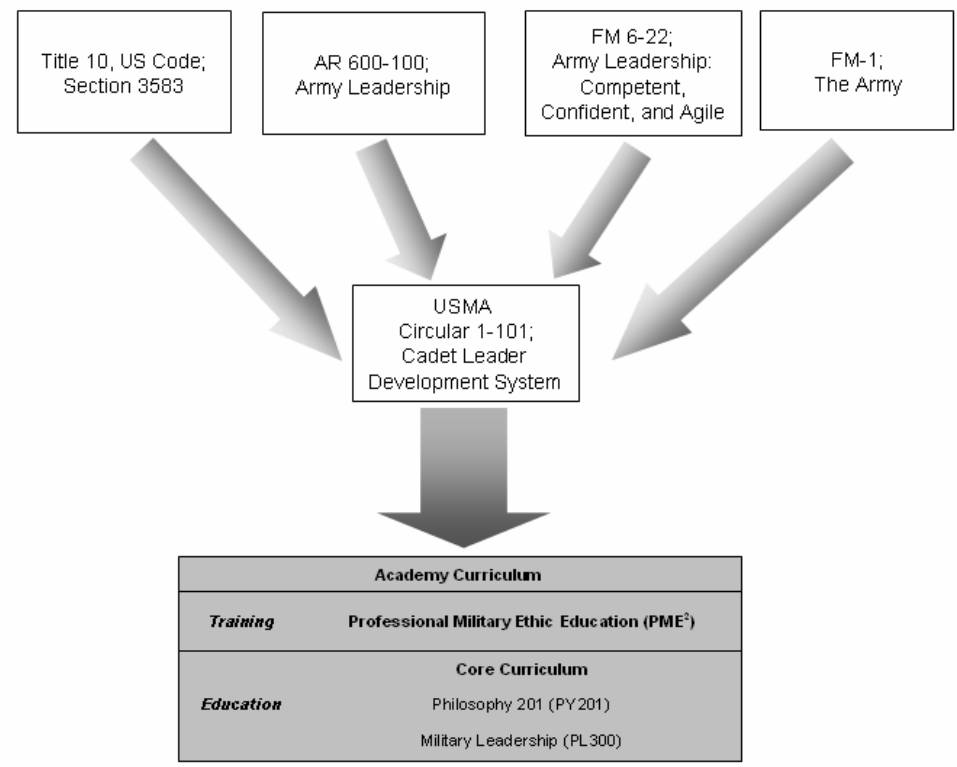

Figure 3. Represents the interpreted environmental engineering program ethics training as a sub-set of the academy curriculum. There is no, single document that encompasses all ethical training within the program. ${ }^{5,6}$ 
This experience includes a robust 70-hour curriculum where cadets participate in a program titled Professional Military Ethic Education $\left(\mathrm{PME}^{2}\right)$. Sessions in this program include small group discussions facilitated by US Army officers that are members of the USMA Faculty (1:15). Faculty in this program typically have more than 10 years of experience in leading and managing among the Army culture. As part of this curriculum, cadets are exposed to ethical situations they may face on and off of the battlefield.

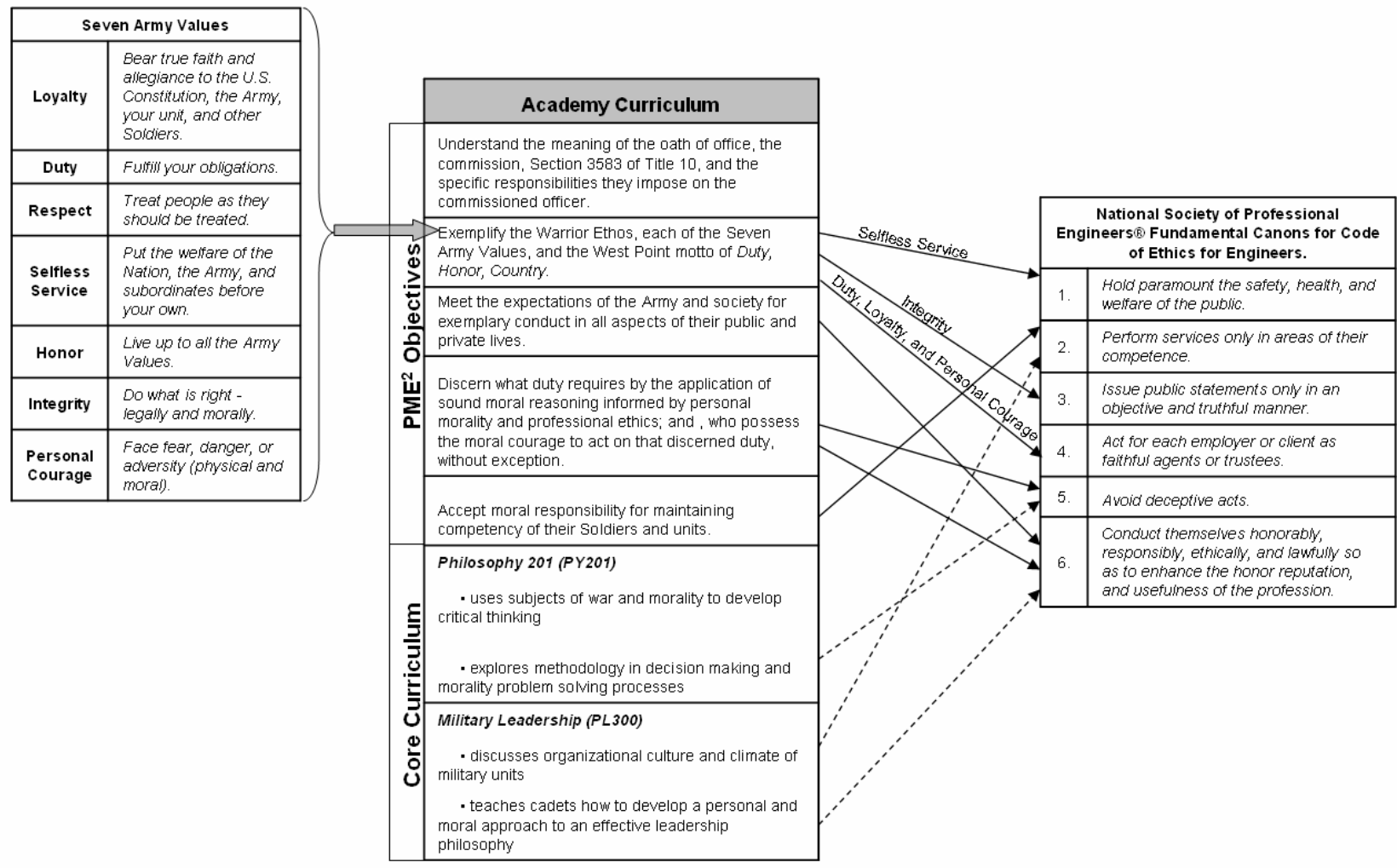

Figure 4. Represents a comparison of the environmental engineering ethics curriculum with the National Society of Professional Engineering Code of Ethics for Engineering. The comparison can be positively correlated to each other using the arrows drawn from the academy curriculum to the NSPE Code of Ethics. The solid lines represent a relationship between the $\mathrm{PME}^{2}$ training and dotted lines represent a relationship between NSPE and the core curriculum. ${ }^{2,5,6}$ 
The $\mathrm{PME}^{2}$ program accomplishes this through case studies or formal discussions about current event issues occurring as a result of the War on Terror. The core curriculum includes two mandatory 40-hour courses taught at the academy. Philosophy 201 (PY201) helps cadets explore and develop their ability to think critically and clearly using the subjects of war and morality. This course is designed to allow cadets to explore the methodology in decision making rather than achieving final answers while using a controversial topic such as war to develop critical and ethical thinking. Although ethical problems are oriented on the military profession, the authors argue that the principles employed are equally applicable to most professions. A deliverable in the course is a paper dealing with a contemporary moral problem, to include analyzing the ethical views studied. Cadets choose issues from currently publicized topics in medical, legal, social, computer, and engineering ethics. Cadets also experience a multidisciplinary study in military Leadership (PL300) that focuses on the organizational culture and ethical climate of military units and allows cadets to develop a personal, moral approach to an effective leadership philosophy.

The academy ethics curriculum, which include the U.S. Army Seven Values, was mapped to the National Society of Professional Engineers (NSPE) published Code of Ethics for Engineers (Figure 4). Based on this comparison, there appears to be much in common between the USMA curriculum and what is required of engineers. A discussion of shortcomings is provided below.

\section{Methodology}

An experiment was conducted to determine if the ethical training acquired by students in their 47 month experience at USMA improves their performance on the FEE. The null hypothesis of this study was: High school students' mean score on 15 sample FEE questions will be lower than the mean score of first class (senior year) cadets on the same 15 sample FEE questions. The study was conducted over a 5 month period and involved 2 populations. Population 1 consisted of students entering their senior year of high school $(n=44)$. Population 2 consisted of first class cadets in several engineering majors, in fall semester in their senior year at the academy $(n=28)$. The populations were chosen to distinguish between those who have completed 40 of the required 47 months of USMA ethics training and education (Population 2) and those who probably have not been exposed to the 47 month ethical training at the academy (Population 1). Most of the cadet engineering students had not yet received formal teaching on engineering ethics because that tends to occur during the spring semester of the senior year. All of the students volunteered to participate in this study. Each population was given the same fifteen question anonymous quiz from Lindeburg and a FEE reference sheet from NCEES. ${ }^{47}$ It was assumed that the sample questions used here are indicative of the questions used on the FEE. Each population was given the time (30 minutes) needed to complete the 15 question quiz, and few students exceeded twenty minutes. The quizzes were hand graded by the authors and a t-test with two-samples assuming unequal variances ( 0.05 probability level) was used to compare the mean scores. 


\section{Results}

The results of the ethics quiz are presented in Table 1. The t-test results demonstrate that the difference between the high school students $(54 \% \pm 11.8 \% ; \mathrm{n}=44)$ and first class cadets $(57 \%$ $\pm 13.4 \% ; \mathrm{n}=28$ ) is not statistically significant (See Table 1 ).

Table 1. Performance by high school students (population 1) cadets in the fall semester of senior year (population 2) on 15 sample FEE ethics questions.

\begin{tabular}{lrr}
\hline & Population 1 & Population 2 \\
\hline Mean & 54 & 57 \\
Variance & 140 & 178 \\
Observations & 44 & 28 \\
Hypothesized Mean Difference & 0 & \\
df & 53 & \\
t Stat & -0.80 & \\
P(T<=t) one-tail & 0.21 & \\
t Critical one-tail & 1.6 & \\
P(T<=t) two-tail & 0.42 & \\
t Critical two-tail & 2.0 & \\
\hline
\end{tabular}

Eight of the 15 sample questions appear to be based on terminology and definitions about ethics and the remainder based on behavioral type questions that portray choices to presented scenarios. No statistical difference (based on t-test) in performance on the types of questions (terminology and behavior) between the sample populations was found.

\section{Discussion}

The robust academy curriculum is well matched with instruction of the NSPE Code of Ethics for Engineers (Figure 4). However one of the areas which may not be congruent between the two codes is the engineer's obligations to employers and clients. The NSPE Code of Ethics for Engineers is explicit and direct in defining the relationships and obligations of engineers, their clients, and their employers. The focus in USMA ethical education and training is a more general in nature and does not include business considerations. The members of the Profession of Arms are distinguished by service to The Constitution of the United States. It is this document alone that instills a nobility of purpose within each member of the Armed Forces and loosely defines the tools used in the ethical decision making process as outlined in the environmental engineering program curriculum Figure (4). ${ }^{2}$

In order to augment the core USMA ethics program the USMA Environmental Engineering Curriculum includes additional instruction on ethics. Discussion of ethics is a central theme in Advanced Environmental Process Design (EV490), taken in the spring semester of the cadets' senior year, with the specific content being a function of the types of projects investigated during a particular semester. However, a review of engineering codes of ethics is always conducted as well as an investigation of the ethical responsibilities of a practitioner to the profession of engineering. The video "Incident at Morales" produced by the National Institute for Engineering Ethics is viewed and discussed during the course. 
Some argue that the underpinnings of an ethical learning process should be focused on helping students develop the ability to recognize ethical situations and that having knowledge of solutions to such contemporary issues will develop the ability of an engineer to become an innovative and ethical problem solver. ${ }^{8,9}$ Others have argued that ethical behavior is achieved through teaching students the value of engineering ethics rather than teaching the values of an ethical engineer. ${ }^{10}$ The ethical learning process might be better instructed and more easily understood as a roadmap through a decision making process. ${ }^{10}$ Shuman et al. ${ }^{9}$ reported that assessment of ethics will be limited until ethical terminology is agreed upon by those responsible for teaching the material and those who are responsible for evaluating the program. Because engineering ethics can depend on specific situations it can be difficult to assess. Scores on dynamics exams are true values with data that is easily analyzed; however ethical situations will not always render the same numerical value like math or science courses. If this argument is accepted, then what is the purpose of assessing ethics on the FEE? One purpose might be to assess the fledgling engineer's understanding of model rules of professional conduct. Another purpose might be to determine if an individual will behave ethically when faced with an ethical dilemma. We found that at approximately seven sample questions used in our study attempted to assess the later. (It is acknowledged that questions used here were not actual FEE questions.) Some individuals might be disadvantaged, in cases where a more conservative answer to an ethical behavior question is not considered correct. Consequently, it is recommended that the FEE not be used as the sole measure to assess attainment of professional practice outcomes.

Because no statistical difference (based on t-test) in performance on the types of questions (terminology and behavior) between the sample populations was found, the USMA core ethics training and education does not appear to improve student performance on the FEE. (As stated above, cadets in the USMA Environmental Engineering Program have additional lessons on engineering ethics, which was not assessed as part of this study.)

New methods for assessing ethical outcomes are warranted. Three options to use in conjunction with the FEE to assess ethical outcomes are offered for consideration. First, introduce ethical processes and decision making skills as a part of the engineering design problems (EDP) that students accomplish as they complete specific courses within an engineering curriculum. In other words, do not wait until the capstone design experience. Asking students to incorporate ethical considerations in an engineering design problem could be graded definitively with a grading rubric and thereby rendering a value or score as a part of the ABET assessment, much like quizzes or homework grades. Inculcation of engineering ethics could then be assessed as students' progress through the engineering program. Secondly, develop a mechanism to help students reflect upon and appreciate social and cultural issues following study abroad experiences. This might be accomplished with a reflective essay. Shuman et al. ${ }^{9}$ suggests that globalization and cultural awareness through study abroad programs develops individuals with a broader understanding and tolerance towards social issues that could aid in future ethical decision making processes. The USMA has a robust study abroad program in two areas; individual advanced development (IAD) and the opportunity for cadets to study abroad for one semester. Third, administer the Defining Issues Test (DIT). The DIT may be a viable instrument for assessing the attainment engineering ethics outcomes because the DIT can be used as an assessment for moral reasoning and is widely recognized through hundreds of 
studies on moral reasoning. ${ }^{11}$ The assessment occurs both before and after ethical training and education has occurred in the form of a pre- and post-testing.

\section{Conclusion}

Evaluation of whether individuals will act ethically in the future is challenging to assess. Although there much in common between the USMA core ethical education and training programs and NSPE Code of Ethics for Engineers, the core USMA program does not adequately prepare students for the ethics section of the FEE. Additional instruction on employer, client and engineer relationships is required. Moreover, use of the FEE to assess engineering ethics, by itself, may not be sufficient to demonstrate attainment of outcomes associated with engineering ethics. Other assessment instruments, including the DIT, might provide more insight into the value of an engineering ethics educational program.

"The views expressed herein are those of the author and do not purport to reflect the position of the United States Military Academy, the Department of the Army, or the Department of Defense."

\section{Bibliography}

1. Merriam-Webster Online Dictionary. http://www.m-w.com/dictionary/ethics, accessed 15 January 2008.

2. FM-1, The Army, 14 June 2005, http://www.army.mil/fm1, accessed 17 December 2007.

3. Accreditation Board of Engineering and Technology, Engineering Criteria 2000, ABET website, http://www.abet.org/eac, accessed 4 December 2007.

4. National Council of Examiners For Engineering And Surveying, Fundamentals of Engineering SuppliedReference Handbook, Seventh Edition, 2005, pp. 99-100.

5. FM 6-22, Army Leadership: Competent, Confident, and Agile, October 2006, http://usacac.army.mil/CAC/CAL/FM6_22.pdf, accessed 14 December 2007.

6. FM 27-10, The Law of Land Warfare, July 1956, http://www.afsc.army.mil/gc/files/FM27-10.pdf, accessed 14 December 2007.

7. Lindeburg, Michael R., FE Review Manual, Second Edition, Professional Publications, Inc., 2006, pp. XVII-1 XVII-5.

8. Richards, Larry G., M. Gorman, "Using Case Studies to Teach Engineering Design and Ethics, Proceedings, 2004 American Society for Engineering Education Annual Conference \& Exposition.

9. Shuman, Larry J., M. Besterfield-Sacre, J. McGourty, "The ABET "Professional Skills" - Can They Be Taught? Can They Be Assessed?", Journal of Engineering Education, Vol. 94, No. 1., 2005, pp. 41-55. 
10. Pfatteicher, Sarah K.A., “Teaching vs. Preaching: EC2000 and the Engineering Ethics Dilemma”, Journal of Engineering Education, Vol. 90, No. 1, 2001, pp. 137-142.

11. Self, Donnie J., E. M. Ellison, “Teaching Engineering Ethics: Assessment of Its Influence on Moral Reasoning Skills", Journal of Engineering Education, Vol. 87, No. 1, 1998, pp. 29-34.

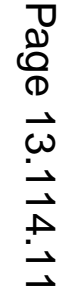

